\title{
Disciplinaridade e redenção nos estudos performativos
}

\section{Fernando Matos Oliveira}

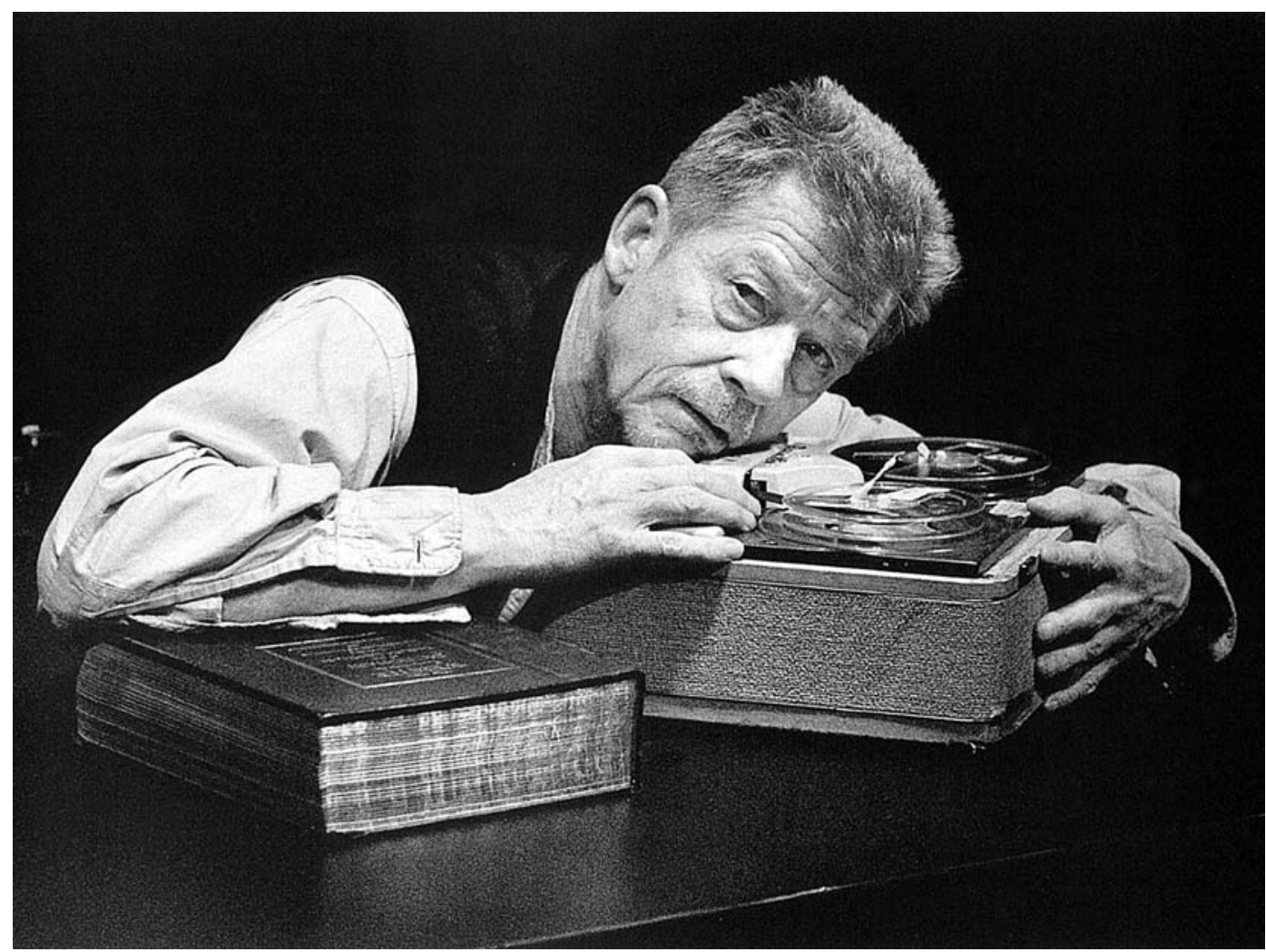

A última bobina de Krapp de Samuel Beckett, 1999 (John Hurt), fot. John Haynes.

\section{Antes de começar}

Paira um certo tom redentor sobre os estudos performativos. Tratarei brevemente da natureza e da persistência deste tom, recorrendo sempre que necessário à institucionalização do próprio território performativo. 0 acesso à historicidade de um determinado campo facilita a detecção das suas dominantes, mas pode também dizernos algo sobre o léxico silenciado pela força de novos valores e de novas atitudes. 0 que se segue implica algo como uma sismografia estilística, deduzida a partir da escrita sobre a performance. A argumentação organizase em torno de quatro aspectos complementares: (a) a conexão entre estética e redenção na modernidade; (b) a dramatização da tópica redentora no processo de constituição disciplinar dos estudos performativos; (c) as consequências hermenêuticas da recuperação "presencial" e aurática a que temos assistido recentemente; (d) por fim, defenderei a manutenção de ratio e sensorium no discurso performativo, com uma referência especial ao projecto Flatland, de Patrícia Portela.
Estética, modernidade e redenção

Antes mesmo das apropriações recentes, o conceito de redenção surge-nos (ainda) como uma derivação daquele défice que conduziu Immanuel Kant ao domínio do estético. Vale a pena esboçar a origem desta redenção fundadora, pelo menos no sentido em que esta institui o campo (e a semântica) a partir do qual podemos detectar oscilações, interpretações restritivas ou o refluxo celebratório, por exemplo, sob a forma de um certo fetichismo performativo, muito comum na contemporaneidade. A redenção em causa mantém, pois, contiguidades com a viragem estética na obra de Kant. Poderá parecer imprudente querer entrar hoje em território performativo pela porta da estética kantiana, justamente quando este discurso se representa a si próprio com ambições disciplinares que em certos momentos ameaçam despedir o círculo hermenêutico inerente a uma estética do gosto e do belo. Talvez fosse de recordar que o autor da Crítica da faculdade do juizo chega a confrontar o estético com os seus limites, com a própria possibilidade do sentido e com o abismo do 
Mammame

coreografia de Jean-Claude

Gallotta, 1985,

fot. Jean-Pierre Maurin.
Hamlet: A Monologue,

enc. e interpretação de

Bob Wilson, 1995,

fot. Tilde De Tullio.
Marquard sugere que 0 estético emerge em virtude de um bloqueio na passagem da "razão cientifica" como força dominante, para a "razăo

histórica". Neste momento intervalar, o estético aparece como uma oportunidade e uma saida para quem lograva afastar-se da ciência mas

não conseguia reencontrar-se com a história: "O apelo do estético surge do impasse na passagem de uma filosofia da ciência para uma filosofia da história" silêncio e da possessão. Ao situar o sublime no intervalo entre o sensivel e o supra-sensivel, sugere ao leitor um espaço informe, suficientemente lato para incluir a ordem do puro acontecer que abre o conhecido ensaio de Peggy Phelan, sobre a ontologia da performance: "A única vida da performance dá-se no presente" (cf. Phelan 1998:171).

Nos termos da narrativa proposta por Odo Marquard, numa síntese notável da evolução do pensamento kantiano, a emergência e a explicitação do estético na modernidade não deveria ser entendida como uma simples especificação discursiva, anexa às inúmeras explicações do mundo postas em marcha pelo ímpeto sistematizador do lluminismo (cf. Marquard 1989:21-34). É certo que a emergência do argumento estético pode ser estudada em diversos autores, entre Shaftesbury e Baumgarten, mas Kant revela como nenhum outro a pretensão universal da conexão estética na modernidade, pois no seu pensamento a arte não vincula o artista estritamente ao domínio artístico, cabendo-Ihe antes a tarefa de assumir um compromisso com o que é propriamente humano.

Como chegamos a esta situação? Por que se explicita o estético na modernidade? 0 que há para redimir? Em primeiro lugar, a demarcação da filosofia relativamente ao universo teológico fez com que a própria razão moderna viesse a incorporar (e a secularizar) a demanda redentora. A tradição filosófica chamou a esta busca "emancipação". 0 impeto emancipatório está de facto presente na "razão científica", definindo todo o seu programa físicomatemático. No entanto, após a Crítica da razão pura, Kant conclui que a ciência não está em condições de garantir por si só a compreensão da totalidade humana, nem a compreensão do humano como totalidade. A censura factual (Faktenzensur) exercida pela razão pura, apenas aceita o mundo traduzido em percepções medidas pelo instrumentário científico. Esta cegueira dos factos não estava em condições de perceber o sentido do mundo histórico, motivo para a Crítica da faculdade do juizo
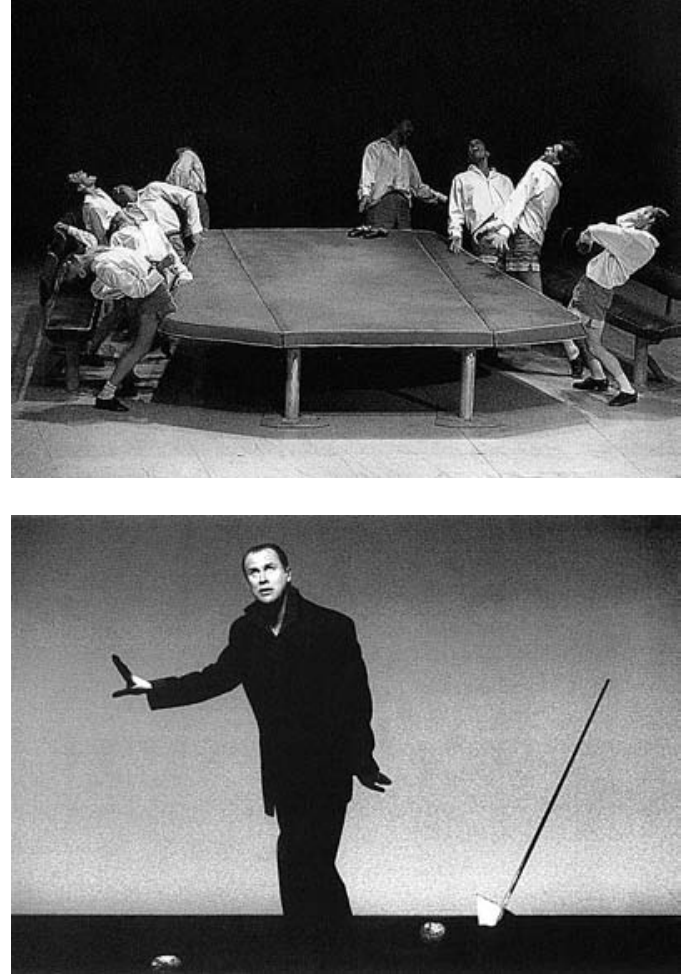

completar, e a seu modo culminar, o edifício transcendental do autor alemão. Em segundo lugar, Marquard lembra que a passagem para o estético ocorre após Kant ter confirmado a impossibilidade da redenção por via da "razão histórica"1 ou da "razão moral". Nesta última, a redenção apenas nos chegaria como preceito anteposto ao próprio real, faltando-Ihe por este motivo capacidade para a prossecução redentora: o mundo dos valores e dos conceitos pode enunciar o que devemos ser, mas não "é", como nós "somos". A "razão moral" não teria assim poder suficiente sobre o mundo.

0 que faz o autor da terceira crítica perante o espectro de uma razão destituida de poder sobre as coisas humanas? Apelo ainda para a sintese de Marquard, justamente num momento em que se refere ao núcleo da resposta "estética" de Kant. Perante a ameaça da despossessão, a razão deveria reagir com astúcia:

[D]everia sobreviver procurando por todos os meios algo que no mundo sensivel pudesse representar a razão e o seu propósito. A isto chamamos hoje, quando tal se verifica, sublimação; é o método ovode-cuco: o que a razão não consegue engendrar sozinha, deve ser engendrado no ninho dos instintos. Esta possibilidade supõe a existência de instintos, e de interesses, capazes de renunciar ao interesse posto na prossecução dos seus próprios objectivos. A terceira critica de Kant (...) é uma pesquisa arrojada, operando com os meios mais subtis, em busca dos "interesses desinteressados" - em busca de uma "natureza racional" situada além do mundo exacto. (id.:31)

0 mundo sensivel a que Kant finalmente recorre para efectuar a redenção, como é sabido, tem o seu epicentro na questão do gosto. Este é submetido a uma dupla racionalização, nas secções dedicadas à "analítica do belo" e à "analítica do sublime". Se o estético, como temos vindo a observar, nos aparece desde o início comprometido com um movimento redentor, estamos agora a chegar propriamente aos modos dessa redenção. 0 assunto pede 


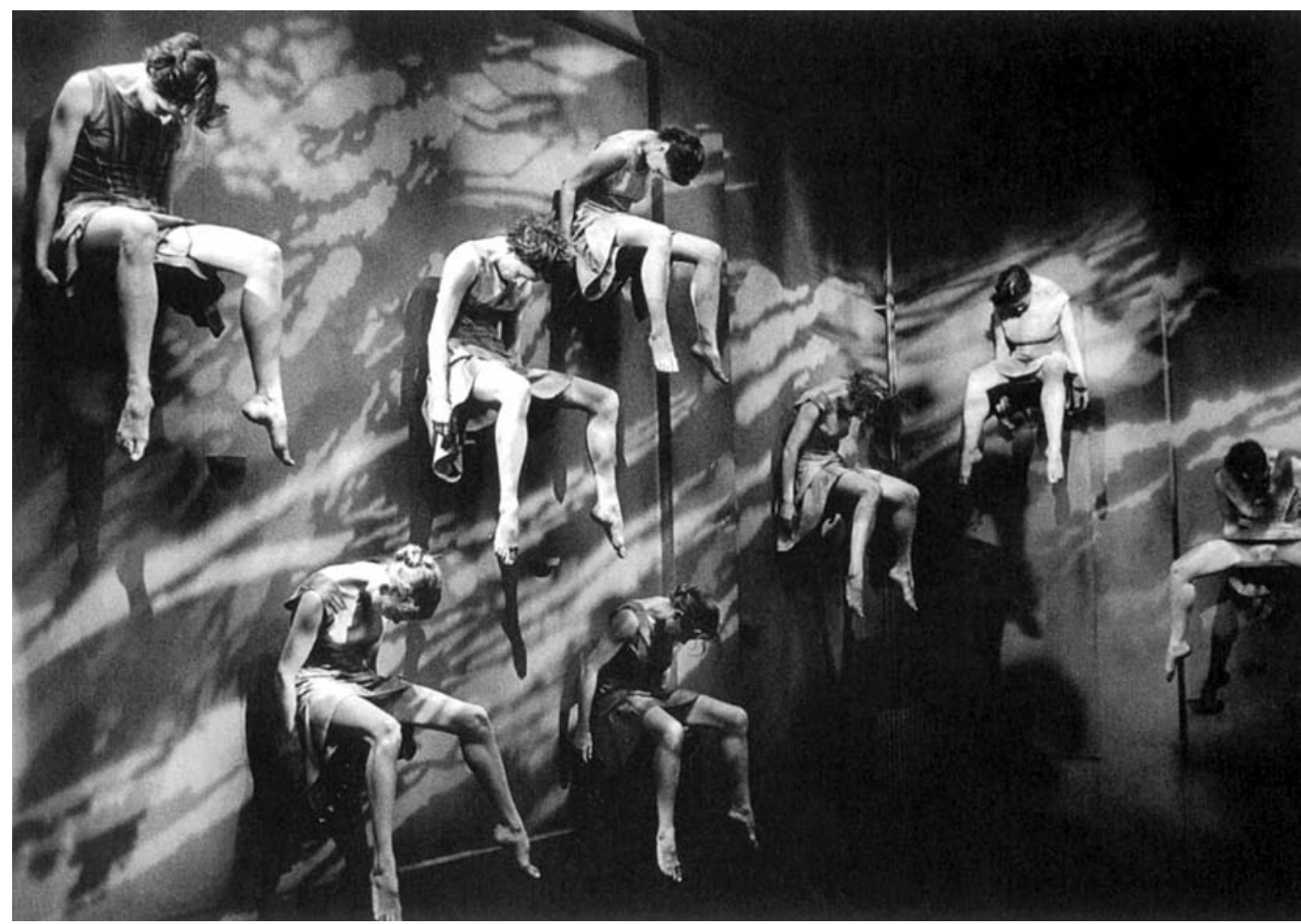

uma derradeira especificação, pois é precisamente aqui que podemos fazer remontar o tom redentor nos estudos performativos, desde sempre vinculados a um ethos presencial e sensivel, com pretensões nitidamente diferenciadoras em relação às demais tradições disciplinares.

A sublimação operada pelo estético obriga-o a um regime de significação específico, diverso da significação quotidiana. Na célebre secção $\$ 59$ da Terceira Crítica, este regime define-se como sendo um processo de simbolização (Kant 1992: 260-264). As hipotitoses a que o autor recorre para ilustrar o processo de simbolização permitem-lhe, além disso, acondicionar no seio do artístico a faculdade da imaginação, sancionando assim a sua proeminência entre as demais faculdades. Repare-se que a lógica da sublimação sobrevive nas duas hipotitoses referidas por Kant - o Estado como "corpo animado" e o Estado como "máquina" -, pois estas deferem o estético, separam-no da acção directa sobre o mundo. Nos seus termos, representam "em ambos os casos porém só 'simbolicamente' " (id.:261). Mas no texto kantiano ficamos sem saber exactamente se a simbolização se propõe orientar de facto a constituição e o funcionamento do Estado, por um lado, ou se apenas pode fazer o luto (compensatório) do Estado mal governado e dos danos causados pela razão científica, por outro. Afirmações como "O belo é símbolo do moralmente bom" não o esclarecem. 0 que fica, e o que agora interessa especialmente, não é tanto o quadro metafísico, sequer a concordância do gosto ou o sensus communis que Kant pressupõe, mas sobretudo o facto de as modalidades desta simbolização redentora nos colocarem perante um quadro conceptual que veio a perseguir o trânsito do estético até aos nossos dias. Podemos reconduzir as alternativas em causa à nomenclatura de Marquard: entre uma simbolização como "instrumento" e uma simbolização como Ersatz, Kant desejou a primeira, mas apenas nos providenciou a segunda, justamente a que nos coloca perante um substituto redentor, perante uma compensação perseguida e celebrada pelo estético.

Os estudos performativos acentuam duplamente a argumentação redentora, pois além de o seu objecto acumular um extraordinário capital sensivel, participando de modo inteiro no sensorium que rodeia o tal "ninho dos instintos", aparece-nos simultaneamente comprometido com as vanguardas de Novecentos e, não menos importante, com os procedimentos "instrumentais" que as caracterizaram. Nas próximas secções retomo brevemente esta vinculação fundadora, antes de chegar ao ponto central: a crítica tem vindo a insistir numa estética da performatividade demasiado próxima de um Erzatz performativo. No limite, esta associação segregaria os elementos constitutivos da própria performatividade, ameaçando liquidar qualquer possibilidade de resistência instrumental, de refracção institucional, conceptual ou até mesmo hermenêutica.

\section{Disciplinaridade}

Os estudos performativos mobilizam hoje um vasto conjunto de tradições disciplinares, entre a antropologia, a filosofia, a sociologia, a linguística, os estudos teatrais e os estudos artísticos em geral. 0 carácter aberto e inclusivo do campo une-se em torno de um conceito lato de performance enquanto "ação", o seu mínimo denominador comum. Numa sintese recente, Richard Schechner, também autor de um trabalho criativo ligado ao Performance Group (1967-1980), escrevia sobre a infância da área, a especificidade do seu objecto e sobre o núcleo conceptual que hoje organiza as suas sobreposições disciplinares: "A performance deve ser entendida como um largo spectrum ou um continuum de acções humanas, oscilando entre o ritual, o jogo, o desporto, o entretenimento popular, as artes performativas (teatro, dança, música) e as acções da vida quotidiana, incluindo o desempenho de papéis sociais, profissionais, raciais, de género ou de classe, bem como o acto de curar (do xamanismo à cirurgia), os 


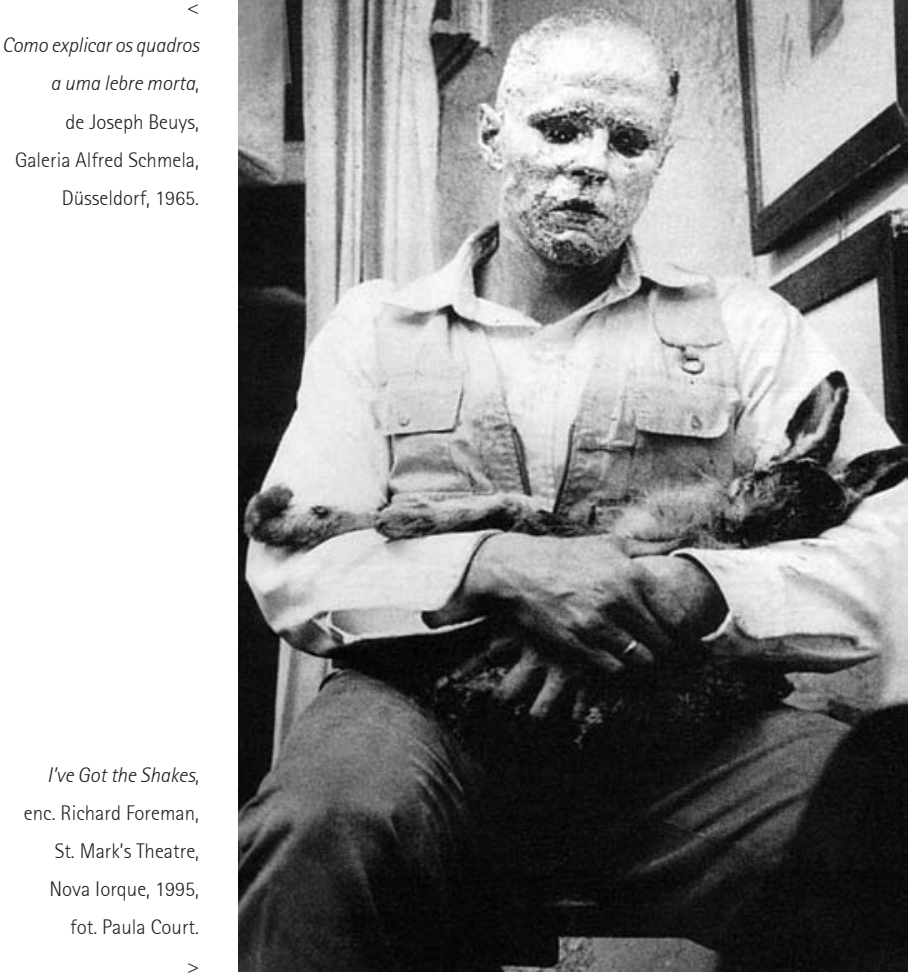

media e a Internet" (Schechner 2003 :2). Neste sentido lato, qualquer "acção" humana pode ser lida "como" performance. Impõe-se então uma restrição prévia: o tom redentor a que me refiro diz respeito sobretudo às artes performativas.

Historicamente, a relação diferida com o estético foi um dos pontos críticos na articulação entre a crítica e os estudos performativos, pois estes vinham desafiar a disciplinaridade instalada de um modo mais profundo do que a ansiedade diferenciadora que atravessara os estudos teatrais, mais sujeitos à pressão textual do referente literário. A transdisciplinaridade solicitada pela performance, como viria a suceder no caso dos estudos culturais, dificultou a sua afirmação institucional, mas não impediu que o seu apelo inclusivo a disseminasse por territórios mais ou menos instituidos, como a antropologia os estudos artísticos; entrou inclusive no discurso de uma série de eventos culturais e de iniciativas editoriais, promovidas por agremiações mais próximas das suas práticas.

A emergência da performance foi especialmente marcada pelo tipo de redenção instrumental ambicionado pelas vanguardas. A este propósito, poder-se-ia originar a performance em três momentos complementares: (a) nas práticas desenvolvidas pelas vanguardas do início do século $X X$, (b) no impeto contestatário e contra-cultural das décadas de sessenta e de setenta (c) e, com um cariz auto-reflexivo renovado, nas práticas latamente associadas ao que hoje chamamos performance art. Esta última disposição artística vem a designar um conjunto amplo de experiências, mobilizando suportes, materiais e expressões tão diversas como a pintura, o teatro, a música, a dança ou a literatura. 0 homo performans da cena contemporânea originou-se nesta conjunção tripartida. Estamos perante um conglomerado histórico de onde emergiu um corpus conceptual que se mantém no centro do discurso performativo. Experimentação, processualidade e resistência à autonomia do estético formam algumas das suas atitudes

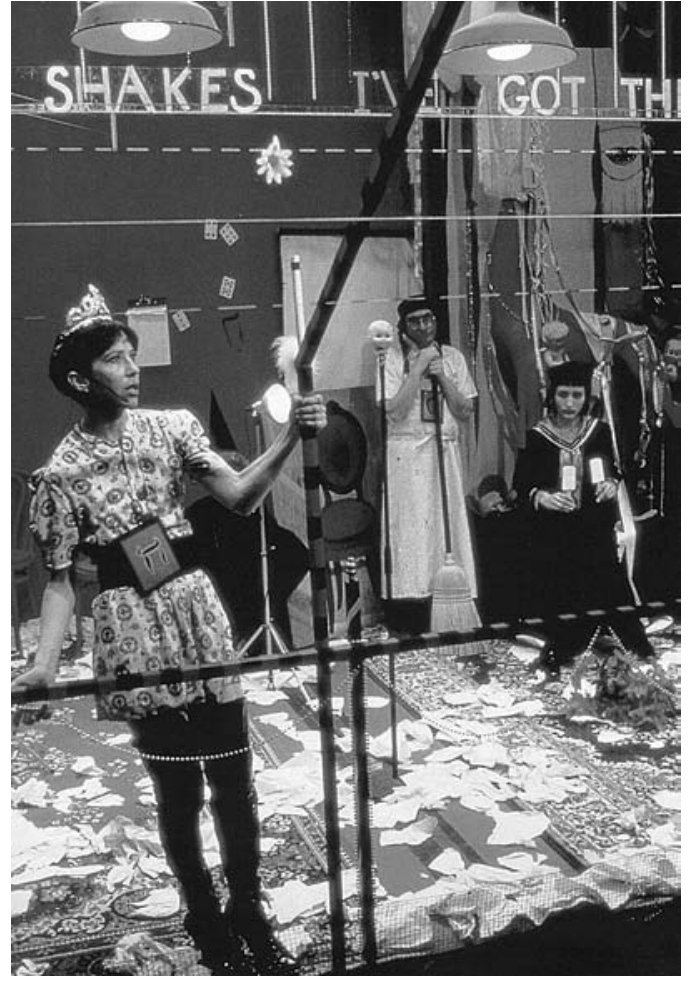

centrais, a par do apelo receptivo e participatório, do questionamento da forma orgânica, da contrafacção dos protolocos inerentes ao campo artístico ou da apropriação da (pré-)expressividade quotidiana. A sua enorme abertura disciplinar e conceptual gerou um léxico reconhecivel na paisagem crítica, organizado em torno de conceitos como corpo, movimento, presença, liveness, happening, acção, interacção, energia ou instalação.

Pese o débito ritualista e primitivista de alguns dos seus protagonistas, mormente os de extracção expressionista e pós-expressionista, a performance surge fortemente vinculada à redenção "instrumental" inerente à sua emergência vanguardista. A seu modo, o performer é uma figura que reage aos impasses da narrativa estética no Ocidente. A relação intensa entre a arte conceptual e a performance, por exemplo, representou uma das respostas mais enfáticas a esta situação de bloqueio histórico: a apropriação performativa do conceptualismo artístico retira-o do domínio das ideias puras, para Ihe conferir uma materialidade e uma processualidade que se pretendia mais resistente ao acantonamento (social e político) do estético. Nas últimas décadas, o amplexo semântico deste projecto performativo de cariz "instrumental" alargou-se exponencialmente, incluindo sintagmas como experimental performance, living theatre, body art, intercultural performance, environmental theatre, guerrilla performance ou camp performance. Em todos estes aglomerados conceptuais, geralmente desenvolvidos num plano simultaneamente reflexivo e criativo, a performatividade propõe formas de intervenção na ordem do histórico e na ordem do estético. 0 engajamento performativo pretendeu realmente contrariar o formalismo asséptico do modernismo.

0 carácter intempestivo da agenda política da década de sessenta prolongou e de certa forma radicalizou o gestus instrumental. Perante a mediatização da experiência veiculada pelos novos meios técnicos, o acontecer presencial associado à performance torna-se ainda mais contrastante. 

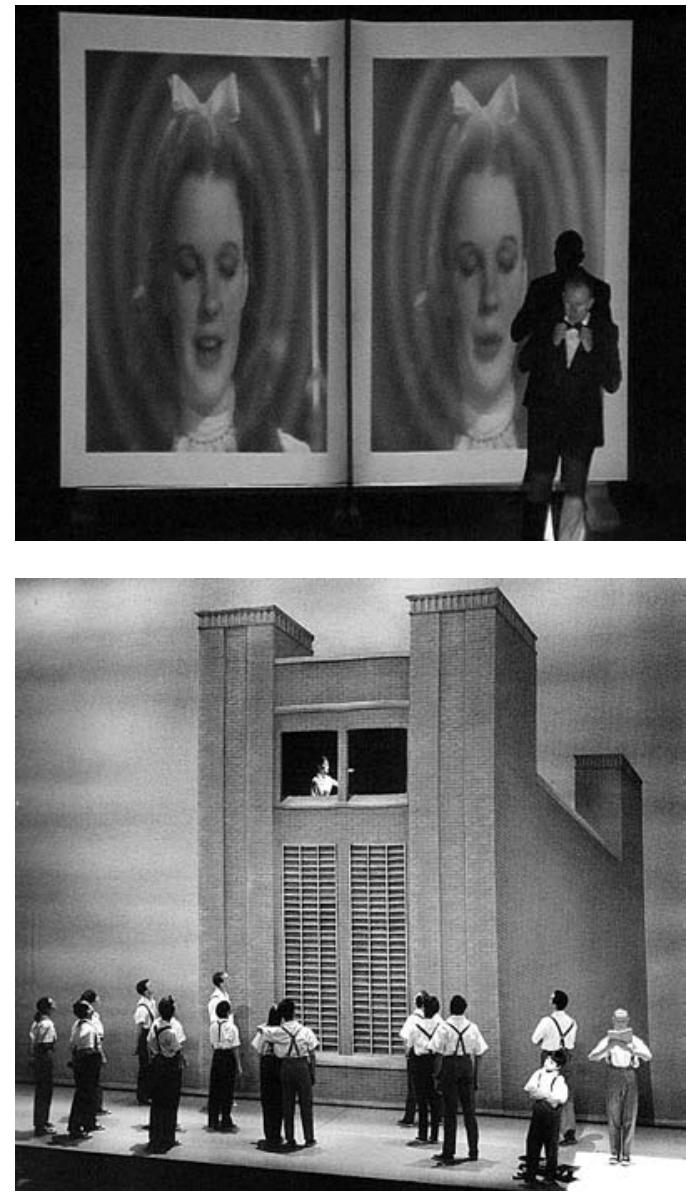

0 carácter disciplinarmente reactivo da performance, num contexto crescente de mediatização, foi já sugerido por autoras como Peggy Phelan (cf. Phelan 1993 e 1998). Ainda assim, a sua insistência na presentificação absoluta do evento performativo, tal como a ideia de uma performatividade resistente à tirania do visível, prometendo um devir "não-marcado" pela vigilância institucional ou política, constitui uma tentativa crítica de salvar a performance das apropriações fetichistas do objecto artístico, muito comuns no museu contemporâneo. Digamos que a autora efectua aqui um recuo estratégico, nem sempre seguido pela crítica contemporânea, como veremos. Perante o fascínio ou a insinuação aurática de um objecto investido de propriedades únicas - imaginemos a aparição de um corpo, tornando-se presente -, a autora busca na ontologia da performance sobretudo um argumento (e um compromisso) que the possa garantir alguma capacidade de controlo interpretativo. Em vez de enfeitiçar o observador, o objecto-performance é integrado na política discursiva e investido de propriedades emancipadoras. Tal hipótese

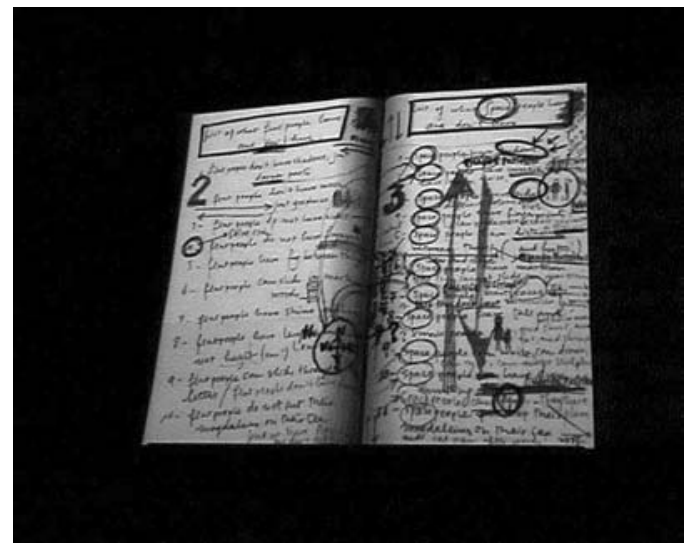

Flatland I,

de Patricia Portela

Clube Estefania /

Festival X, 2004

(Anton Skrypiciel)

fot. Patricia Bateira.

Flatland I,

de Patricia Portela,

Clube Estefania /

Festival X, 2004,

fot. Patricia Bateira.

não deixa de constituir uma extrapolação engenhosa daquele insight que levou uma notável performer e ensaista como Adrian Piper a operar a redenção do fetichismo artístico (muito frequente na forma como o museu actual relembra o gabinete de curiosidades setecentista), interpretando-o como emanação performativa de um ser autêntico, responsável último pela sua criação (Piper 1996: 51-61). A singularidade do objecto artístico seria assim garantida pela singularidade do criador. Repare-se que esta hipótese deve algo à redenção instrumental que venho referindo. Contrariamente à arte tradicional, a arte performativa deveria autorizar presencialmente a intencionalidade criadora; assistiríamos, como em nenhum outro lugar, ao instante próprio da delegação estética da energia social, sob o olhar dos próprios espectadores, sem aparato mediador.

A persuasão performativa promove assim a redução máxima do lapso temporal entre produção e recepção artísticas, criando situações de colaboração e de interacção com grande potencial emancipador. Não admira, pois, que a autencidade performativa se aproxime em Phelan de uma quase pedagogia (ou teologia?) da redenção. 0 último capitulo de um dos seus livros intitula-se precisamente "Posfácio: anotações sobre a esperança - para os meus alunos" (Phelan 1993: 167-180). Nestas páginas, a colaboração performativa invade a sala de aula, embora a autora não ceda imediatamente à política da visibilidade e da representação que enforma o debate público sobre as identidades e o poder. A cena proposta aspira a uma pedagogia performativa capaz de ensinar a ler a contingência absoluta do real, capaz de interpretar a fragilidade de cada aparição, de pensar o visível e de confrontar criticamente o rasto da presença: "É através deste esforço em caminhar (e viver) o sobressalto entre o Eu e o Outro - e não o esforço de passarmos para um ou outro lado - que descobriremos a verdadeira esperança" (id.:174).
Einstein on the Beach, enc. Bob Wilson, 1976, fot. Tilde De Tullio. 


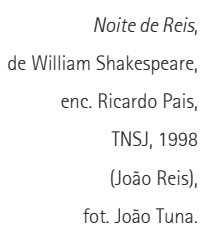

Aparições liminares

A redenção performativa não seguiu sempre o caminho, porventura demasiado sofisticado, sugerido por Peggy Phelan. A politização do espaço artístico aproximou a performance das questões imediatas da representação e da visibilidade, nem sempre cuidando dos riscos inerentes. Por vezes, a sua pretensão política apegou-se a simetrias representacionais demasiado indexadas aos modelos sob suspeita. Contudo, há algo mais perturbador no horizonte crítico.

Nos últimos anos, a ontologia da presença e a entronização crítica do "acontecer" têm servido para algo mais do que a demonização das reproduções e simulações do mundo contemporâneo. Sendo certo que um entendimento performativo do real contribuiu para liquidar a metafísica da presença, mostrando-nos que as coisas se definem através das suas manifestações concretas (e não pela fidelidade platónica a uma essência anterior), a agenda crítica vem associando a performatividade a uma autenticidade redentora. A questão suscita comentário porque esta insistência tende a expulsar a performance do círculo hermenêutico, arredando-a de modo particularmente definitivo de qualquer pretensão reflexiva. Com efeito, se entendermos a performatividade como o encontro pleno com um corpo e/ou evento absolutamente contingentes, como se processa interpretação? Como podemos "citar" algo evanescente, como nos pede a tradição hermenêutica? A celebração puramente sensoria do evento performativo implicaria uma restrição "instrumental", quando não uma ocultação da gramática (e da ratio) que organiza a própria materialidade desse evento celebrado.

A restrição hermenêutica contida na reactivação crítica da presença poderia deduzir-se a partir da leitura desse impressionante tour de force produzido por Hans Ulrich Gumbrecht, em defesa de um êxtase redentor, bónus derradeiro para um homem que honestamente admite precisar de momentos encantadores na velhice (cf. Gumbrecht 2004: 143). A presença coincide aqui exactamente com o não-hermenêutico, com o que resiste ao sentido, a bem da sintonia com o mundo, do estar "no" mundo. Os sinais da proliferação crítica da presença redentora estão um pouco por todo o lado, embora sujeitos a diversos enquadramentos conceptuais, frequentemente em clave pedagógica, como sucede num recente compêndio dedicado ao ensino dos estudos performativos (cf. Stucky/Wimmer 2002). Além da pedagogia da esperança que vimos em Peggy Phelan, o leitor poderá reencontrar o desejo redentor em dois livros recentes, ambos filiados na ensaistica germânica, respectivamente de Erika FischerLichte e de Dieter Mersch. Com os cuidados extremos de quem escreve num tempo pós-iluminista, Erika FischerLichte, encerra o seu monumental estudo sobre a estética da performatividade com um sugestivo capítulo intitulado "O reencantamento do mundo" (Fischer-Lichte 2004: 318362). 0 mecanismo de amplificação redentora parte igualmente da co-presença física de actores e espectadores, para desaguar numa performatividade de tipo liminar. Se a "fronteira" é o lugar da separação e da lei, a ancestralidade mágica do espaço "liminar" convocado pela performance anteciparia a possibilidade da transição e da transformação. Mais do que isso, para a autora, a performance constituiria a passagem da lógica da fronteira para a lógica da liminaridade. Façamos a pergunta: este reencantamento não sugere um movimento regressivo? A resposta surge no parágrafo final, onde se anuncia como "novo" iluminismo: "Este não pede ao Homem para dominar a natureza (...), nem sequer o obriga a tal, pelo contrário, convida-o a experimentar-se a si próprio e ao mundo, não excluindo, mas incluindo - comportando-se na vida como nas representações artísticas" (id.:362). Não deixa de ser extraordinário, além de testemunhar o zénite redentor contido no discurso sobre a performance, que uma autora capaz de operar análises minuciosas dos processos de 

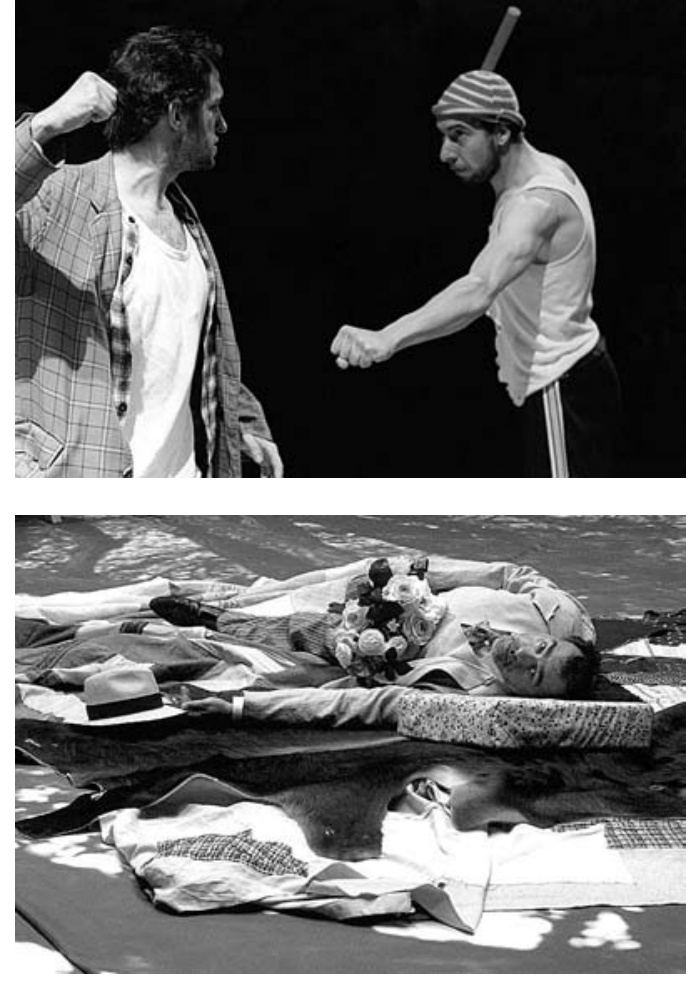

significação espectacular, capaz de tipificar exaustivamente a materialidade, a corporeidade e a temporalidade da performance, decida concluir desta forma tal empreendimento.

Dieter Mersch, por outro lado, radica a sua "ética da performatividade" num acontecimento que aspira substituir a lógica moderna da força e do poder por uma soberania negociada e processual (Mersch 2002:289298). A precariedade desta soberania, enquanto nãopoder, investiria a transitoriedade performativa de uma virtude quase misteriosa. Só um sujeito em estado de "abandono" poderia sintonizar com a performance. 0 seu projecto tem a particularidade de assumir o que outros apenas insinuam, apresentando o acontecer performativo como uma manifestação aurática, afim à experiência (estética) do sublime. Dai a sintonia com o informe, com o presente absoluto, enfim, com a esfera das aparições. Mas este modo de reencantar o mundo, mormente numa época marcada pela estetização indiferenciada do quotidiano, é um gesto crítico deveras arriscado. A sociedade do bem-estar acelerou nas últimas décadas a estetização do quotidiano, a massificação do lazer e fomentou a multiplicação e a internalização da experiência, aspectos que dispõem o sujeito à participação performativa. A forma como o hedonismo contemporâneo amplifica e intensifica a erótica da presença e do acontecimento sintoniza com toda uma série de apetites e disponibilidades sensoriais que podem eventualmente segregar, também no plano do discurso crítico, práticas performativas que ousassem um mínimo de renúncia reflexiva.

\section{Ratio e sensorium}

Tendo contado com a colaboração da produtora Irmã Lúcia Efeitos Especiais, Flatland, de Patrícia Portela, é um projecto que problematiza a ideia de uma estética da aparição. Gostaria de o convocar brevemente, pois tem a vantagem adicional de nos confrontar com o significado da passagem da obra ao acontecimento, mutação decisiva para a emergência de uma cultura da performatividade. Flatland adaptou com alguma liberalidade o clássico homónimo de ficção científica, publicado em 1884, por Edwin A. Abbott. Ao longo da sessão, os espectadores assistem ao esforço do Homem Plano para escapar às limitações do mundo bidimensional que o aprisiona nas páginas de um livro gigante, colocado no centro do espaço cénico. Após uma série de interrogações sobre a perspectiva, o Homem descobre que só poderia experimentar o mundo a três dimensões caso existissem espectadores a olhar para ele.

Patrícia Portela conjuga neste espectáculo o vídeo, a música, a escrita animada e a instalação. Esta fusão de meios não propõe uma celebração gratuita do multimédia, nem se destina à exibição dos artifícios técnicos da pósmodernidade, próximos de uma nova espécie de transcendência. A acumulação de meios não se destina ao reencantamento do mundo e até o seu "acontecer" se constitui nos arredores da corporeidade exponenciada que define grande parte dos eventos performativos, pois o centro é ocupado pelo livro aberto, funcionando simultaneamente como objecto e como tela de projecção. A singularidade do conjunto resiste a tipificações imediatas. Poderiamos descrever o espectáculo como performance, vídeo-instalação, performance-instalação, espectáculo multimédia, entre outras possibilidades. Uma constatação parece indiscutivel: em Flatland acontecem coisas estranhas, desde logo, coisas muito estranhas aos nossos hábitos perceptivos.

Um dos aspectos mais estimulantes neste projecto consiste precisamente no modo como faz da presença o seu próprio "tema". 0 Homem Plano sente-se insatisfeito, porque toma consciência do défice presencial associado à sua existência a duas dimensões. De certa forma, a busca da terceira dimensão equivale a uma tentativa de

\section{2 perdidos numa noite suja, de Plinio Marcos, enc. Silvia Brito, A Escola da Noite, 2004 (Ricardo Correia e Carlos Marques), fot. Augusto Baptista.}

\section{OTio Vânia,} de Anton Tchékhov, enc. Nuno Carinhas, ASSéDIO / Ensemble / TNSJ, 2005 (João Cardoso), fot. João Tuna.
${ }^{2}$ Duas das suas três partes foram já apresentadas publicamente, em $2004 \mathrm{e}$ 2005; a terceira foi antecipada em Flat Summer, uma versão site-specific da totalidade do projecto, desenvolvida na última edição do Citemor (2005). Interessame sobretudo a primeira parte: Flatland I - Para cima e não para norte. 
aperfeiçoamento da presença, demasiado limitada à superfície plana da página. Esta coincidência confere ao objecto-livro uma ressonância singular. Flatland encena o próprio acto da constituição performativa da presença, pois o nosso Homem apenas se emancipa do universo livresco quando cooptado pelo olhar (presentificador) dos espectadores. Este olhar é verdadeiramente um acto performativo e faz com que este espectáculo produza e testemunhe a efemeridade da presença. É justamente neste momento crítico que a sedução da presença revela a sua faceta "voyeurista": o Homem Plano precisa de ver e de ser visto para existir no mundo propriamente dito, o mundo a três dimensões. A presença torna-se assim passivel de instrumentalização, algo a que uma estética do encantamento redentor não poderia aceder. Este aspecto seria depois explorado pela autora, na segunda e terceira partes do projecto, quando o Homem tornado presente sequestra os espectadores para garantir o seu olhar.

A primeira parte parece então empenhada em precipitar o questionamento posterior da presença num mundo mediático. Mais do que isso, o espectáculo posiciona-se criticamente quanto à felicidade do encontro presencial. Neste caso, tal não garante uma bonificação nem cumpre no imediato a promesse de bonheur que o Ocidente tende a dilatar no tempo. A aparição do Homem Plano a três dimensões resulta antes de um processo de construção e de manipulação da perspectiva. 0 seu trajecto "existencial" lembra-nos que aquilo que existe, aquilo que vemos ou podemos ver, resulta de um condicionamento perceptivo. Ele salta do livro gigante também para nos dizer que as questões da presença, como as questões da visibilidade, resultam sempre dessa encenação perceptiva do real, ainda quando as coisas aparentam uma proximidade absoluta.

No seu todo, a trilogia Flatland remete obviamente para a insustentabilidade da presença na cena mediática contemporânea, dominada pela proliferação paradoxal de efeitos-de-presença, em suportes desmaterializados. E todavia significativo que, na organização das suas partes, a passagem do mundo a duas dimensões para o mundo tridimensional mantenha o Homem Plano em permanente negociação presencial. Longe de uma pacificação, o sujeito existe entre o zapping dos grafemas e o zapping das imagens. Flatland sugere-nos, então, uma performatividade simultaneamente empenhada nos sentidos "e" na cognição, pois a reflexão sobre a perspectiva, desenvolvida na primeira parte, sem evitar a abstracção, constitui um momento de "iniciação", permitindo ao espectador observar a máquina (re)presentacional a fazer-se.

A forma do livro é aqui um indutor semântico importante. Além de se apresentar como objecto-instalação e de servir com eficácia a encenação do mundo a duas dimensões, o livro é o mais importante elemento na definição do espaço performativo. A localização central estabiliza a perspectiva e equilibra, por oposição, o trânsito intenso de signos sobre as suas páginas. Finalmente, 0 livro gigante acumula o estatuto de arquivo ancestral. Deste modo, contradiz também a tendência das artes performativas para a constituição de materialidades dessemantizadas, através do uso de objectos e de formas fora do seu contexto habitual, ou mesmo através da criação de materialidades de grande contingência formal. Sendo várias coisas ao mesmo tempo, este livro mantém-se como livro.

Flatland sugere-nos ainda que a processualidade se pode mover para o centro conceptual da performance, sem excluir aprioristicamente as técnicas de reprodução ou o lúdico, evidente em algumas das projecções. Flatland é em boa parte um notável exercício de escrita performativa, actualizando através do vídeo e da animação as experiências gráficas da sua ascendência vanguardista. As páginas do livro gigante são inscritas com letras e imagens em ritmos diferentes. A ocupação deste espaço branco processa-se através de estratégias evocativas e citacionais, por vezes, declaradamente elípticas, outras vezes, completadas pela imagem e pelo desenho sonoro de Christoph de Boeck. 0 espectáculo de Patrícia Portela relativiza uma concepção da performatividade demasiado centrada no corpo copresente. A co-presença física, sendo importante, é aqui um instante adiado até quase ao último segundo, quando a voz (de Anton Skrypiciel) e a escrita do Homem Plano visitam fugazmente o mundo a três dimensões.

\section{Referências bibliográficas}

CARLSON, Marvin (1996) Performance: A Critical Introduction, London, Routledge.

FISCHER-LICHTE, Erika (2004) Ästhetik des Performativen, Frankfurt am Main, Suhrkamp Verlag.

GUMBRECHT, Hans Ulrich (2004), The Production of Presence: What Meaning Cannot Convey, Stanford / California, Stanford University Press.

KANT, Immanuel (1992), Critica da faculdade do juizo, tradução e notas de António Marques e Valério Rohden, Lisboa, IN-CM.

MARQUARD, Odo (1986), Aesthetica und Anasthetica: Philosophische Überlegungen, Paderborn/München/Wien, Ferdinand Schöningh.

MERSCH, Dieter (2002) Ereignis und Aura: Untersuchungen zu einer Ästhetik des Performativen, Frankfurt, Suhrkamp Verlag.

PHELAN, Peggy (1991), Unmarked: The Politics of Performance, London, Routledge.

- - (1998), "A ontologia da performance: representação sem reprodução", Revista de comunicação e linguagens, nº 24, pp. 171-192.

PIPER, Adrian (1996), Out of Order, Out of Sight: Selected Writings in Art Criticism (1962-1992), Vol. 2, Cambridge/Massachusetts, MIT Press. SCHECHNER, Richard (1988), Performance Theory, New York / London, Routledge.

- - (2002) Performance Studies: An Introduction, New York / London, Routledge.

STUCKY, Nathan / WIMMER, Cynthia (eds.) (2002) Teaching Performing Studies, Carbondale \&t Edwardsville, Southern Illinois University Press. 